\title{
CURRÍculo escolar, PRÁtICA PEDAGógICA e SABERES DISCIPLINARES DA HISTÓRIA
}

\author{
SCHOOL CURRICULUM, PEDAGOGICAL PRACTICE AND SUBJECT KNOWLEDGES \\ OF HISTORY
}

André Mendes Salles ${ }^{1}$

\begin{abstract}
RESUMO: O presente texto objetiva refletir sobre as relações teóricas entre currículo, disciplina escolar, prática pedagógica e saber disciplinar, com foco para a História acadêmica e escolar. Parte-se de uma perspectiva teórica crítica do currículo, que o entende como uma construção social negociada, enredada em relações de poder. Nesse sentido, assinala-se a necessidade de investimentos cada vez maiores em pesquisas acerca da História das disciplinas escolares, para que se compreenda como elas foram sendo socialmente construídas em cada contexto histórico, social, político, cultural e curricular de cada país e em cada momento específico, assim como as relações estabelecidas com os saberes disciplinares correspondentes e com a prática pedagógica.
\end{abstract}

Palavras-chave: Currículo. Conhecimento escolar. Prática pedagógica. Saber disciplinar. Ensino de história.

\begin{abstract}
The present work aims to think over the theoretical relations among curriculum, school subject, pedagogical practice and subject knowledge, focusing on History - at colleges and schools. It starts from a critical theoretical perspective of the curriculum, which comprehends it as a negotiated social construction, entangled in power relations. In this way, it is highlighted the necessity of higher investments in researches about the History of school subjects, in order to comprehend how they were socially built on each country historical, social, political, cultural and curricular context and on each specific moment, as well as the established relations with the correspondent subject knowledges and with the pedagogical practice.
\end{abstract}

Keywords: Curriculum. School knowledge. Pedagogical practice. Subject knowledge. History teaching.

\footnotetext{
1 Doutor em Educação pela Universidade Federal de Pernambuco (UFPE). Professor adjunto da Universidade Federal do Rio Grande do Norte (UFRN), lotado no Departamento de História (Campus Caicó). Docente e orientador no Mestrado Profissional em Ensino de História da Universidade Federal de Pernambuco (PROFHISTÓRIA-UFPE).
} 


\section{Introdução}

Ivor Goodson, prestigiado educador e pesquisador da educação, assinala que o currículo estaria longe de se constituir em um elemento neutro de seleção cultural, sendo um "terreno de grande contestação, fragmentação e mudança" (GOODSON, 1997, p. 27), fruto de "um longo e contínuo conflito" (GOODSON, 2012, p. 24). Para o autor britânico, os estudos sócio-históricos sobre o currículo devem ser enfatizados, partindo-se do pressuposto de que "qualquer afirmação sobre currículo deve estar localizada no período histórico em questão" (GOODSON, 2008, p. 14), tendo em vista que o mesmo é uma "construção social" (GOODSON, 1997) e, portanto, se refere a um espaço-tempo específico. É nesse sentido que, para Goodson, a elaboração curricular "pode ser considerada um processo pelo qual se inventa tradições" (GOODSON, 2012, p. 112).

Giroux (1983), por sua parte, baseando-se em Young, argumenta que não é possível separar conhecimento de poder. Aquilo que é considerado como conhecimento válido, selecionado em determinada época, é tecido a partir de relações de poder. Nóvoa (1997, p. 9), baseando-se em Tomaz Tadeu da Silva, afirma que o estudo da História do currículo pode nos ajudar a "ver o conhecimento escolar como um artefato social e histórico sujeito a mudanças e flutuações, e não como uma realidade fixa e atemporal". Contudo, destaca que:

\footnotetext{
O objectivo central da História do currículo não é descrever como se estruturava o conhecimento escolar no passado, mas antes compreender como é que uma determinada 'construção social' foi trazida até ao presente influenciando as nossas práticas e concepções do ensino (NÓVOA, p. 10, grifo nosso).
}

Ancorado na História das disciplinas escolares, torna-se importante perceber como o conhecimento histórico escolar foi se (re)configurando nos currículos e livros didáticos da Educação Básica no Brasil, tendo em vista sua presença nesses documentos e suportes educativos desde pelo menos o século XIX. Como dito anteriormente, partilhamos do entendimento de Goodson (1997, 2012), para quem o currículo e os conhecimentos por ele selecionados constituem-se em uma construção social. Nesse sentido, partimos da perspectiva 
de que o conhecimento histórico escolar presente no currículo foi/é socialmente construído, em cada contexto histórico, social, político, cultural e curricular de cada país e em cada momento específico.

Forquin (1993) aponta que a educação escolar - e o currículo mais especificamente - constituem-se de uma "seleção no interior da cultura". Não obstante, assim como Goodson, assinala que esta seleção estaria longe de se constituir em um movimento neutro e desinteressado. Para Forquin (1993), a educação "transmite, no máximo, algo da cultura, elementos de cultura [...]", partindo do entendimento de que "a escola não ensina senão uma parte extremamente restrita de tudo o que constitui a experiência coletiva, a cultura viva de uma comunidade humana" (FORQUIN, 1993, p. 15), em outras palavras, "sua versão autorizada". Nesse sentido, o currículo, mais do que um percurso formativo, "seguido por alguém", é um percurso "prescrito para alguém" (FORQUIN, 1993, p. 16, 22).

O pesquisador francês, no entanto, assinala que o currículo se constitui não apenas de uma "seleção no interior da cultura", mas também de uma "reelaboração didática" desses conteúdos selecionados.

[...] a educação escolar não se limita a fazer uma seleção entre saberes e os materiais culturais disponíveis num dado momento, ela deve também, para torná-los efetivamente transmissíveis, efetivamente assimiláveis às jovens gerações, entregar-se a um imenso trabalho de reorganização, de reestruturação, ou de 'transposição didática' (FORQUIN, 1993, p. 16, grifo nosso).

Tendo Forquin como uma de nossas referências, podemos inferir, previamente, que o conhecimento escolar a respeito da Guerra do Paraguai ${ }^{2}$, só para citar um exemplo, passou por um duplo processo de constituição. Primeiro, tendo sido considerado um relevante evento histórico, com inegáveis consequências para os países envolvidos - e levando-se em conta, sobretudo, o

\footnotetext{
2 Utilizamos como exemplo o conhecimento escolar Guerra do Paraguai por este já se constituir em um assunto amplamente discutido pelo autor. Mas podemos estender este exemplo, guardadas as devidas proporções, para os conhecimentos históricos escolares de uma maneira mais ampla. Em outras palavras, o conhecimento histórico escolar, em geral, passa por um duplo processo de constituição, primeiro precisa ser considerado um evento de relevância, digno a figurar nos currículos e livros escolares; em seguida, precisa-se realizar o processo de 'reelaboração didática' desse evento histórico selecionado. É evidente que essas seleções e elaborações são sempre construções histórica e socialmente delimitadas, enredadas em teias de poderes.
} 
seu forte potencial para a construção de uma identidade nacional -, a Guerra do Paraguai foi selecionada para fazer parte do rol dos conhecimentos escolares. Por integrar o conjunto dos conhecimentos escolares, foi necessário proceder a sua "reelaboração didática", processo do qual o livro didático é parte integrante, sendo este o segundo processo de sua constituição. E isto nos leva a evidenciar, na análise, as diferentes manifestações e níveis do currículo.

Goodson (2012, p. 22), por sua vez, destaca que o currículo é "formulado numa variedade de áreas e níveis" e que, portanto, deve-se ter o cuidado de distinguir entre o "currículo escrito" e "o currículo como atividade em sala de aula". Defende que os estudos curriculares não devem restringir-se ao primeiro. Importante sublinhar que, para Goodson, o currículo enquanto uma construção social se dá não apenas ao nível da prescrição, mas também ao nível do processo e da prática. Nesse sentido, a prática curricular do professor é entendida enquanto uma construção social negociada.

O que está prescrito não é necessariamente o que é apreendido, e o que se planeja não é necessariamente o que acontece. Todavia, como já afirmamos, isto não implica que devamos abandonar nossos estudos sobre prescrição como formulação social, e adotar, de forma única, o prático. Pelo contrário, devemos procurar estudar a construção social do currículo tanto em nível de prescrição como em nível de interação (GOODSON, 2012, p. 78).

Goodson (2008, p. 56) destaca ainda que:

O trabalho dos professores, seu labor profissional, seus interesses e instrumentos pessoais estão no coração da educação. Mudar a educação é mudar o trabalho do professor e vice-versa. A delicada micropolítica de negociar novas práticas profissionais não pode ser executada apenas por um mandato e uma inspeção externa. É preciso que haja renegociação externa.

Para Forquin (1993, p. 24), por sua parte, "uma teoria do currículo supõe sempre levar em consideração o que se passa no interior da 'caixa preta' das salas de aula e das escolas e não apenas o que se passa na entrada e na saída". Forquin, baseando-se em Lawton, destaca que tanto as escolas como os 
professores em seus fazeres cotidianos, relacionados à organização do ensino, realizam diferentes tipos de seleções no interior da cultura.

Considerando que os estudos sobre o currículo devem levar em conta não apenas o "currículo escrito", mas também "o currículo como atividade em sala de aula", e tendo em vista que a prática curricular docente é uma construção social negociada (GOODSON, 2012) e que os professores, na organização e consecução de sua prática, realizam sempre algum tipo de seleção no interior da cultura (FORQUIN, 1993), é que passamos a entender a necessidade de se tecer reflexões e considerações acerca de como o conhecimento histórico escolar se configura enquanto prática curricular dos professores, quer dizer, suas escolhas, suas ênfases e omissões em relação aos saberes escolares da História.

\section{A organização curricular por disciplinas}

Goodson (1997) é um dos autores que tece contundentes críticas à organização curricular fragmentada em disciplinas escolares. Para ele, a perspectiva disciplinar poderia frustrar uma reflexão maior referente aos objetivos sociais da educação, uma vez que a maioria das preocupações relacionadas a essa organização curricular se daria em torno das especificidades de cada disciplina escolar. Considera, todavia, que a disciplina escolar faz parte de uma "estrutura mais ampla que incorpora e define os objectivos e possibilidades sociais do ensino" (GOODSON, 1997, p. 31). Para o autor, as disciplinas escolares são apenas uma maneira, hegemônica na atualidade, de organizar o currículo, mas não a única possível.

Young (2007, 2011), ao contrário de Goodson (1997), defende a estruturação curricular baseada em disciplinas escolares. Para o primeiro, o conhecimento nas sociedades modernas passou a ser cada vez mais especializado e produzido em universidades e centros de pesquisa e, nesse sentido, haveria vantagens para as disciplinas escolares estarem associadas às disciplinas acadêmico-científicas, uma vez que teriam seus conhecimentos validados, tornando-se mais confiáveis. Além disso, teriam a vantagem de trabalhar em torno de conceitos estruturadores das disciplinas, o que abriria, 
portanto, a possibilidade de realizar generalizações, com potencial de mobilizar os saberes para o entendimento e transformação da realidade, se configurando enquanto um conhecimento poderoso. É por tal razão que, para Young (2011, p. 614), "os estudantes não vão à escola para aprender o que já sabem".

Goodson (1997), ao estudar a história dos currículos escolares, chega a apontar que a atual organização curricular, em que as disciplinas escolares estão associadas às disciplinas universitárias é, também, ela mesma, uma construção social, e, portanto, não deve ser entendida como um processo natural. O autor exemplifica a questão trazendo à tona o conflito curricular existente na Inglaterra do século XIX em torno do modelo escolar de Ciências, destacando o conflito entre as ciências das coisas comuns com a ciência pura (de caráter acadêmico), tendo sido esta última o modelo escolar/curricular vitorioso. Se, naquele momento, tivesse sido a ciência das coisas comuns o formato vitorioso da disciplina escolar Ciências, não se teria a associação direta/imediata da disciplina escolar à disciplina/área acadêmica correspondente, daí o caráter histórico e social das disciplinas escolares.

Goodson (1997) enfatiza o caráter conflituoso em relação ao próprio formato de disciplina escolar a ser implementado na escola - ou a ser considerado válido - tendo em vista suas determinações históricas e sociais. Tais apontamentos de Goodson (1997) indicam não apenas que a disciplina escolar é uma construção histórica e social, mas que ela está enredada em um processo de construção no qual as relações de poder não podem ser descartadas, se se quer entender o contexto de sua produção. Em outras palavras, os grupos sociais que tiverem maior poder de influência, terão maiores possibilidades de determinar o currículo e, portanto, o formato de disciplina escolar a ser implementado na escola. É nesse sentido, e apontando tais argumentos, que Goodson se apresentará como um crítico da ideia de transposição didática, mostrando que a lógica da associação entre disciplina escolar e disciplina acadêmica é uma construção social, eivada de relações de poder.

Outro autor que se apresenta como um crítico da teoria da transposição didática é o francês André Chervel, pesquisador da história das disciplinas escolares. Baseando-se em pesquisas históricas sobre a Gramática escolar 
francesa, o autor chega a defender a autonomia dos saberes escolares frente aos saberes acadêmicos - ou ciência de referência. Não obstante, sem desconsiderar a relativa autonomia das disciplinas escolares, concordamos com as ponderações feitas por Bittencourt (2004, p. 39-40):

\begin{abstract}
O problema enfrentado por quem parte do pressuposto da relativa autonomia das disciplinas escolares em relação às ciências de referência encontra-se na diversidade de disciplinas ou saberes escolares e na forma pela qual cada uma delas se constituiu. Questiona-se, por exemplo, se as trajetórias das diversas disciplinas escolares seriam semelhantes à da história da Gramática nas escolas francesas, conforme estudo de Chervel. Assim, tem sido fundamental conhecer a história das disciplinas para identificar os pressupostos que possibilitam entender os liames e as diferenças entre a disciplina escolar e as ciências de referência, uma vez que cada disciplina possui uma história.
\end{abstract}

Apesar de considerarmos a relevância dos estudos de Chervel (1990), acreditamos que não podemos generalizar as conclusões a que o autor chegou para todas as disciplinas escolares, irrestritamente, muito menos para contextos escolares de diferentes países. Com isso, não estamos desconsiderando que muitos saberes escolares foram e têm sido criados "pela própria escola, na escola e para a escola", como sustenta Chervel (1990, p. 181). Não é nossa intenção subestimar o potencial da escola para criar seus próprios saberes, ou ainda negar que os saberes criados na e pela escola possam influenciar os saberes chamados eruditos.

\title{
2. A disciplina escolar História
}

Como pondera Cardoso (2008), a História escolar não se constitui em uma pura simplificação da "História dos historiadores", inclusive, pela própria distinção entre as funções sociais dessas duas instâncias de produção - a escola e a universidade/centros de pesquisa. Apesar disso, não podemos negligenciar os vínculos existentes entre elas hoje no Brasil. Se a História escolar é completamente autônoma frente à História acadêmica, como supõe Cardoso (2008), poderíamos questionar: o que se faz então nas universidades e demais 
instituições de ensino superior, nos cursos de formação de professores de História? Nesse sentido, Aryana Costa $(2008$, p. 7$)$ pondera:

[...] está claro para nós que se perde muito ao se considerar a Didática da História somente como um conjunto de procedimentos para transferir o conhecimento de uma instância à outra. No entanto, não admitimos que não há uma transferência a ser feita. Talvez o termo "transferência" soe um tanto quanto preconceituoso e por isso possa ser reposto por outro, como por exemplo, relação, intercâmbio, conexão. Se a "História dos Historiadores" não tem nada a dizer para a escola, então qual é a sua função? Auto-deleite? Acreditamos que é exatamente nesta relação entre a História dos historiadores e a História escolar que reside o ponto chave de diálogo com a Teoria da História.

Deste modo, assim como Costa (2008), partimos do entendimento da existência de uma relação de proximidade e conexão entre a "História dos historiadores" e a História escolar, ainda que tal relação se faça acompanhar por um processo de "reelaboração didática" (FORQUIN, 1993), que constitui e configura os conhecimentos históricos escolares em cada tempo e contexto. Reconhecer a existência dessa relação de proximidade e conexão entre a História acadêmica e a escolar não é, necessariamente, defender que esta última seja pautada por uma simples relação de 'transferência' mecânica de uma instância a outra.

Gabriel e Monteiro (2014, p. 27)3, apesar de considerarem o conhecimento escolar enquanto uma "construção epistemológica própria e específica", quer dizer, uma "criação da cultura escolar", reconhecem que o mesmo "mantém diálogos necessários e contínuos com o conhecimento acadêmico/científico de referência, no caso, a Teoria da História e a historiografia". Nesse sentido, as autoras anunciam a relevância da teoria da transposição didática, de Chevallard, e apontam que o reconhecimento em torno da existência de um processo de "didatização do saber" (CHEVALLARD, 1991) não significa, necessariamente, desconsiderar as "especificidades epistemológicas" do conhecimento escolar, tendo em vista que os saberes de referência não são as únicas fontes para o saber escolar. Assim:

\footnotetext{
${ }^{3}$ As referidas autoras baseiam-se em Forquin para apontar as especificidades epistemológicas do conhecimento escolar como criação da cultura escolar.
} 
[...] Duas contribuições efetivamente renovadoras decorrem da utilização do conceito de conhecimento escolar e de transposição didática. O primeiro conceito, considerado na perspectiva que reconhece a especificidade epistemológica de sua construção, que tem a dimensão educativa como estruturante na sua constituição e que implica um diálogo contínuo e não hierarquizado com o conhecimento da disciplina científica, no caso, a Teoria da História e a historiografia, para sua reelaboração/renovação/atualização. (GABRIEL; MONTEIRO, 2014, p. 33, grifo nosso).

Desta forma, consideramos, assim como Gabriel e Monteiro (2014, p. 34), que:

[...] a análise das criações originais do conhecimento escolar possibilita, pois, a compreensão de questões relativas à didática e ao currículo, articuladas àquelas pertinentes à historiografia e ao desenvolvimento de alternativas inovadoras e teoricamente fundamentadas para o ensino/aprendizagem da História. [...]. Essa análise, por sua vez, exemplo vivo dos processos implícitos na produção do conhecimento escolar em História, numa perspectiva que assume que a incorporação de contribuições teóricas do campo da ciência de referência não produz uma réplica, mas sim um conhecimento com características originais, próprias da cultura escolar (grifo nosso).

Alice Casimiro Lopes (1997, p. 564), preferindo usar o termo mediação didática no lugar de transposição, considerado por ela como reducionista, tendo em vista que o termo pode transmitir uma ideia de "reprodução, movimento de transportar de um lugar a outro, sem alterações", afirma:

A mediação didática não deve, por conseguinte, ser interpretada como um mal necessário ou como um defeito a ser suplantado. A didatização não é meramente um processo de vulgarização ou adaptação de um conhecimento produzido em outras instâncias (universidades e centros de pesquisa). Cabe à escola o papel de tornar acessível um conhecimento para que possa ser transmitido. Contudo, isso não the confere a característica de instância meramente reprodutora de conhecimentos. $\mathbf{O}$ trabalho de didatização acaba por implicar, necessariamente, uma atividade de produção original. Por conseguinte, devemos recusar a imagem passiva da escola como receptáculo de subprodutos culturais da sociedade. Ao contrário, devemos resgatar e salientar o papel da escola como 
socializadora/produtora de conhecimento (LOPES, 1997, p. 566, grifo nosso).

Ao considerar a complexidade do conceito de conhecimento escolar, evidenciadas nas reflexões anteriormente expostas, e ao entender que o saber disciplinar da História é uma importante fonte para a constituição dos saberes históricos escolares, que passamos, a seguir, a refletir sobre a prática pedagógica e a prática epistemológica em relação à disciplina História.

\section{Disciplina História: prática pedagógica e prática epistemológica}

Entendemos, como posto por João Francisco de Souza $(2007,2009)$, que a prática docente é uma das dimensões da prática pedagógica, sendo esta última o "fazer da instituição escolar" (SOUZA, 2009, p. 27). Em outras palavras, devemos ter o cuidado de não reduzir a segunda à primeira. O referido autor assinala ser mais adequada a expressão práxis pedagógica para se referir a ação coletiva que acontece na instituição educativa. Nesse sentido, aponta a:

[...] concepção de Práxis Pedagógica como ação social coletiva da instituição na qual se inter-relacionam, conformando uma unidade: as práticas docente, discente, gestora e epistemológica ou gnosiológica, permeadas pela afetividade na busca de garantir sua contribuição à construção da humanidade do ser humano, em todas as suas feições (SOUZA, 2007, p. 10, grifo do autor).

Segundo João Francisco de Souza, por ser uma "ação social coletiva da instituição", a Práxis Pedagógica é uma:

[...] ação de todos os seus sujeitos (discentes, docentes e gestores), permeada pela afetividade na busca da construção de conhecimentos ou conteúdos pedagógicos (educacionais, instrumentais e operativos) que garantam a construção de condições subjetivas e algumas objetivas do crescimento humano de todos os seus sujeitos (SOUZA, 2007, p. 16). 
Tendo isto em vista, complementa:

\begin{abstract}
A práxis pedagógica são processos educativos em realização, historicamente situados no interior de uma determinada cultura, organizados, de forma intencional, por instituições socialmente para isso designadas, implicando práticas de todos e de cada um de seus sujeitos na construção do conhecimento necessário à atuação social, técnica e tecnológica (SOUZA, 2009, p. 34).
\end{abstract}

Tendo tais perspectivas conceituais em vista, Souza (2009, p. 23, grifo do autor) aponta que todo processo ou percurso formativo em instituições educacionais "não resulta de uma prática docente, mas de uma práxis pedagógica não apenas de uma instituição, mas de várias". Nesse sentido, a formação de um professor de História, por exemplo, não seria o resultado apenas de um conjunto de práticas docentes vivenciadas no curso de formação inicial" ${ }^{4}$ mas da "práxis pedagógica de várias instituições formadoras e de muitas outras experiências formativas que vai vivendo ao longo da vida e de seus ambientes culturais" (SOUZA, 2009, p. 23). Afirmar isso não diminui o peso e a importância da instituição formadora dos profissionais da História.

Além do mais, uma importante dimensão da práxis pedagógica é a prática gnosiológica e/ou epistemológica presente no ato formativo dentro das instituições educacionais. Em relação à História, não podemos olvidar, como apontou Certeau (2011), que ela se configura enquanto uma prática institucionalizada, quer dizer, é uma prática realizada e validada por uma comunidade de pesquisadores/historiadores. Como assinala Dosse (2012, p. 126), a História é uma prática que "deve ser referida a um lugar de enunciação, a uma técnica de saber, ligada à instituição histórica". Nesse sentido, é preciso reconhecer que a formação do professor de História é realizada em instituições específicas que possibilitam que ele tenha acesso a essa comunidade - através dos próprios professores formadores e das leituras da área em que entra em contato no período de sua formação e mesmo em momentos posteriores. Assim,

\footnotetext{
${ }^{4}$ Esse conjunto de práticas docentes se dá, inclusive, em uma instituição específica, conjuntamente com outras práticas e sujeitos, configurando assim uma práxis pedagógica. Como afirma Souza (2009, p. 24), "a professora e o professor não têm prática pedagógica. Têm prática docente. A prática docente é apenas uma das dimensões da prática pedagógica interconectada com a prática gestora, a prática discente e a prática gnosiológica e/ou epistemológica."
} 
tendo em vista que a prática epistemológica se constitui em um dos componentes da práxis pedagógica, portanto, presente no ato educativo em sala de aula, não poderia estar desvinculada, no caso da História escolar, de uma prática historiográfica.

Entendemos, portanto, que os professores, em sua prática docente, mobilizam saberes. Contudo, poderíamos interrogar: Que saberes são esses? Seriam apenas os saberes da ciência de referência? Assim como Monteiro (2007, p. 19), não comungamos da posição segundo a qual o professor é visto como "um técnico cuja atividade profissional consistiria na aplicação rigorosa de teorias e técnicas científicas". Tampouco concordamos com o que quer a racionalidade técnica, para quem "o professor é apenas um canal de transmissão de saberes produzidos por outros" (MONTEIRO, 2007, p. 21), pois tal perspectiva nega a "subjetividade e saberes dos professores e dos alunos como agentes no processo educativo" (MONTEIRO, 2007, p. 22). Consideramos, ao contrário, o caráter plural dos saberes docentes (TARDIF, 2010), inclusive àqueles oriundos da experiência, "constituídos no exercício da prática cotidiana da profissão, fundados no trabalho e no conhecimento do meio" (MONTEIRO, 2001).

Os questionamentos levantados por Tardif (2010) são extremamente importantes como forma de perscrutar sobre os saberes docentes:

Se admitirmos que o saber dos professores não provém de uma
única, mas de várias fontes e de diferentes momentos da história
de vida e da carreira profissional, essa própria diversidade levanta
o problema da unificação e da recomposição dos saberes no e pelo
trabalho. Como os professores amalgamam esses saberes? E, se
há fusão, como ela se opera? Ocorrem contradições, dilemas,
tensões, 'conflitos cognitivos' entre esses saberes? Essa
diversidade dos saberes também traz à tona a questão da
hierarquização efetuada pelos professores. Por exemplo, será que
eles se servem de todos esses saberes da mesma maneira? Será
que privilegiam certos saberes e consideram outros periféricos,
secundários, acessórios? Será que valorizam alguns saberes e
desvalorizam outros? Que princípios regem essas hierarquizações?
(TARDIF, 2010, p. 21).

Acreditamos que as respostas aos questionamentos formulados por Tardif, apesar de extremamente pertinentes para se pensar sobre os saberes docentes 
de uma maneira geral, não podem ser universais. Nesse sentido, falas de professores - sujeitos de pesquisas diversas no campo da Educação, poderão dar luz a alguns desses questionamentos, relacionados especificamente aos saberes disciplinares dos professores e ao conhecimento histórico escolar.

\section{Saberes disciplinares da História}

Entendemos os saberes disciplinares como àqueles que estão relacionados "aos diversos campos do conhecimento historicamente produzidos, que se encontram delimitados e institucionalmente organizados" (BATISTA NETO, 2006, p. 2). Nesse sentido, são "saberes de que dispõe a nossa sociedade, tais como se encontram hoje integrados nas universidades, sob a forma de disciplinas, no interior das faculdades e de cursos distintos". (TARDIF, 2010, p. 38). Importante destacar, ainda, que "são saberes sociais definidos e selecionados pela instituição universitária e incorporados na prática docente" (ALMEIDA; BIAJONE, 2007, p. 286). Compreendemos igualmente como Tardif (2010, p. 38), que "os saberes das disciplinas emergem da tradição cultural e dos grupos sociais produtores de saberes".

Os 'saberes disciplinares da História' são 'saberes específicos', haja vista que se tratam, especificamente, do conhecimento oriundo da disciplina História. Deste modo, como aponta Batista Neto (2006, p. 2), "o termo 'específico' agrega-se aqui como atributo, designando algo próprio de uma espécie de saber. É um saber especializado, porque produzido de forma rigorosa por um corpo de especialistas. Saber específico opor-se-ia assim a saber genérico". Relevante ainda enfatizar, assim como faz o referido autor, que os saberes disciplinares específicos relacionados à História "resultam do processo de seleção na cultura (cf. FORQUIN, 1993) que as instituições de ensino superior (IES) promovem num dado momento para cumprir sua missão formadora" (BATISTA NETO, 2006, p. 2).

Apesar de concordarmos com Tardif (2010) e Batista Neto (2006), de que os saberes disciplinares "se encontram hoje integrados nas universidades, sob a forma de disciplinas, no interior das faculdades e de cursos distintos" 
(TARDIF, 2010, p. 38, grifo nosso), é preciso salientar que os saberes disciplinares da História, no Brasil, existiam muito antes do estabelecimento de instituições de formação para o professor de História em nível superior (IES) ${ }^{5}$. No Brasil, a formação em História em instituições de nível superior só se tornou possível na década de 1930. No contexto brasileiro, portanto, a História se estabeleceu, inicialmente, enquanto um corpo de saber disciplinar socialmente constituído, selecionado, legitimado e organizado por outra instituição que não a universidade: O Instituto Histórico e Geográfico Brasileiro (IHGB) ${ }^{6}$,

Dito isto, entendemos os saberes disciplinares como um conjunto de saberes socialmente construído, selecionado, organizado e legitimado em determinado momento por uma comunidade de especialistas que não atua única e exclusivamente com base no rigor científico, mas também a partir de demandas sociais - contextualizadas historicamente - que estão enredadas em teias de poderes/saberes.

Outro conjunto de saberes presente tanto na formação - inicial e continuada - de professores, quanto na própria prática docente, são os saberes pedagógicos. Relevante deixar claro que, ao atribuirmos aos saberes disciplinares o atributo de "específicos", não estamos desconsiderando que os saberes pedagógicos também o sejam, tendo em vista que esses últimos são saberes produzidos com rigorosidade teórico-metodológica, assim como são portadores de um estatuto epistemológico específico (BATISTA NETO, 2006). Nesse sentido, quando atribuímos a expressão/qualificativo 'específicos' aos saberes disciplinares não estamos partindo da perspectiva que busca hierarquizar esses

\footnotetext{
5 Em concordância com Abud (2008, p. 29), entendemos que "a História como disciplina escolar da escola secundária [brasileira] se efetivou com a criação do Colégio D. Pedro II, no final da regência de Araújo Lima, em 1837". Contudo, como problematiza Bittencourt (2004), a formação dos profissionais de História em nível superior no Brasil só se verificará a partir da década de 1930, com a criação das Faculdades de Filosofia, Ciências e Letras, isto é, basicamente um século depois da criação da História enquanto disciplina escolar. Isto quer dizer que a História, enquanto conhecimento escolar, no Brasil, precedeu a História, enquanto curso superior responsável pela formação dos profissionais da área do magistério.

6 Durante muitas décadas dos séculos XIX e XX, a instituição legitimadora do conhecimento histórico no Brasil foi o Instituto Histórico e Geográfico Brasileiro (IHGB), cuja criação data do mesmo ano do Colégio Pedro II, 1837, e pelas mãos das mesmas forças sociais. Então, não podemos perder de vista que já havia, desde o século XIX, uma produção historiográfica, legitimada pelo IHGB, portanto, em instituição que não a universidade, que influenciava a História escolar e a produção de materiais didáticos da época. É nesse sentido que Abud (2008, p. 29) afirma que "a História disciplina não nasceu sozinha. Foi sua irmã gêmea a História acadêmica".
} 
dois campos de saberes, mas tão somente estamos buscando destacar que, dentre aqueles, o que nos interessa particularmente são os saberes disciplinares da História.

Relevante destacar, ainda, que os saberes disciplinares estão presentes, com destaque de tempo, espaço e poder, na formação - inicial e continuada - de professores, mas não se restringem ao espaço formativo. Os saberes disciplinares são mobilizados pela prática docente, assim como estão sistematizados em pesquisas que se convertem em leituras especializadas, sejam elas oriundas de trabalhos de dissertações, teses e artigos acadêmicos ou como produto do mercado editorial, materializada em livros - autorais e/ou coletivos -, em periódicos de divulgação e, mais recentemente, em sites especializados em História, Educação e ensino.

Outros locais nos quais os saberes disciplinares circulam são nos encontros acadêmicos, em que pesquisadores podem discutir e difundir trabalhos referentes às suas mais recentes pesquisas. No Brasil, podemos citar como exemplo os encontros nacionais e regionais realizados pela Associação Nacional de História (ANPUH), que ocorrem bianualmente. A apropriação de saberes disciplinares, portanto, não está restrita ao processo formativo inicial do professor e do bacharel em História, mas incorpora também a troca entre os pares, em que são possíveis realizar discussões e divulgações de ideias e de resultados de pesquisas, seja através de palestras, conferências, grupos temáticos de discussões ou de publicações em anais de eventos.

\section{Considerações finais}

Buscou-se, ao longo desse texto, refletir sobre as relações teóricas entre currículo, disciplina escolar, prática pedagógica e saber disciplinar, com foco para a História - acadêmica e escolar. Para tanto, partimos de uma perspectiva teórica crítica do currículo, que o entende como uma construção social negociada, enredada em relações de poder, cuja elaboração caracteriza-se como um terreno de disputas em torno da cultura a ser legitimada e a se tornar hegemônica. 
Problematiza-se, na teoria crítica, inclusive, o próprio formato curricular organizado em disciplinas, entendido também como um processo de construção. A associação entre disciplinas escolares e suas ciências de referências também é problematizada, assinalando-se que não se trata de um processo natural. A esse respeito, contudo, Young (2011) enfatiza a importância de as disciplinas escolares estarem associadas à ciência, pois esta seria a forma de conhecimento mais segura e confiável. Em tempos em que terrraplanistas ocupam posição de destaque na formulação de políticas públicas de importantes áreas no Brasil, com crescentes ondas de anti-intelectualismo, tendemos a concordar com Young.

Findamos este texto assinalando a importância de investimentos cada vez maiores em pesquisas acerca da História das disciplinas escolares, para que se compreenda como elas foram sendo socialmente construídas em cada contexto histórico, social, político, cultural e curricular em diferentes tempos e espaços, assim como as relações que elas estabelecem com os saberes disciplinares correspondentes e com a prática pedagógica.

\section{Referências:}

ABUD, Kátia. Currículos de História e políticas públicas: os programas de História do Brasil na escola secundária. In: BITTENCOURT, Circe (org.). O saber histórico na sala de aula. São Paulo: Contexto, 2008. p. 28-41.

ALMEIDA, Patrícia Cristina Albieri de; BIAJONE, Jefferson. Saberes docentes e formação inicial de professores: implicações e desafios para as propostas de formação. Educação e Pesquisa, São Paulo, v. 33, n. 2, p. 281-295, 2007.

BATISTA NETO, José. Saberes pedagógicos e saberes disciplinares específicos: os desafios para o ensino da história. In: ENCONTRO NACIONAL DE DIDÁTICA E PRÁTICA DE ENSINO, 13., 2006, Recife. Anais [...]. Recife: ENDIPE, 2006.

BITTENCOURT, Circe. Ensino de história: fundamentos e métodos. São Paulo: Cortez, 2004.

CARDOSO, Oldimar. Para uma definição de didática da história. Revista Brasileira de História, São Paulo, v. 28, p. 153-170, 2008.

CERTEAU, Michel. A escrita da história. 3. ed. Rio de Janeiro: Forense editora, 2011. 
CHERVEL, André. História das disciplinas escolares: reflexões sobre um campo de pesquisa. Teoria \& Educação, Florianópolis, n. 2, p. 177-229, 1990.

CHEVALLARD, Yves. La transposición didáctica: del saber sabio al saber enseñado. Argentina: Editora Aique, 1991.

COSTA, Aryana. Apologia do ensino de história: a didática da história em Jörn Rüsen. In: ENCONTRO ESTADUAL DA ANPUH HISTÓRIA E HISTORIOGRAFIA: ENTRE O NACIONAL E O REGIONAL, 13., 2008, Guarabira. Anais [...]. Guarabira: Anpuh, 2008. p. 1-9.

DOSSE, François. A história. Tradução Roberto Leal Ferreira. São Paulo: Editora UNESP, 2012.

FORQUIN, Jean-Claude. Escola e cultura: as bases sociais e epistemológicas do conhecimento escolar. Tradução de Guacira Lopes Louro. Porto Alegre: Artes Médicas, 1993.

GABRIEL, Teresa; MONTEIRO, Ana Maria. Currículo de história e narrativa: desafios epistemológicos e apostas políticas. In: MONTEIRO, A.M.F.C.; GABRIEL,C.T.; COSTA,W. da; ARAUJO,C.M. de. (org.). Pesquisa em ensino de história: entre desafios epistemológicos e apostas políticas. Rio de Janeiro: MauadX FAPERJ, 2014. v. 1, p. 23-40.

GIROUX, Henry. Pedagogia Radical: subsídios. São Paulo: Cortez: Autores Associados, 1983.

GOODSON, Yvor. A construção social do currículo. Lisboa: Editora EDUCA, 1997.

GOODSON, Yvor. As políticas de currículo e de escolarização: abordagens históricas. Tradução de Vera Joscelyne. Petrópolis: Vozes, 2008.

GOODSON, Yvor. Currículo: teoria e história. Petrópolis: Vozes, 2012.

LOPES, Alice Casimiro. Conhecimento escolar em química - processo de mediação didática da ciência. Química Nova, São Paulo, v. 20, p. 563-568, 1997.

MONTEIRO, Ana Maria. Professores: entre saberes e práticas. São Paulo: Educação \& Sociedade, São Paulo, v. 22, n. 74, p. 121-142, 2001.

MONTEIRO, Ana Maria. Professores de história: entre saberes e práticas. Rio de Janeiro: Editora Mauad X, 2007.

NÓVOA, António. Nota de Apresentação. In: GOODSON, Yvor. A construção social do currículo. Lisboa: Editora EDUCA, 1997. p. 9-16.

SOUZA, João Francisco de. E a educação popular: quê?? uma pedagogia para fundamentar a educação, inclusive escolar, necessária ao povo brasileiro. Recife: Bagaço, 2007. 
SOUZA, João Francisco de. Prática pedagógica e formação de professores. Recife: Ed. Universitária da UFPE, 2009.

TARDIF, Maurice. Saberes docentes e formação de professores. Petrópolis: Vozes, 2010.

YOUNG, Michael. Para que servem as escolas?. Educ. Soc., Campinas, v. 28, n. 101, p. 1287-1302, set./dez. 2007.

YOUNG, Michael. O futuro da educação em uma sociedade do conhecimento: o argumento radical em defesa de um currículo centrado em disciplinas. Revista Brasileira de Educação, Rio de Janeiro, v. 16, n. 48, set./dez. 2011. 